\title{
Oligodontia in siblings with Ectodermal Dysplasia
}

\author{
Nagaratna PJ ${ }^{1}$, Vidya KB², Chanchala $\mathrm{HP}^{3}$
}

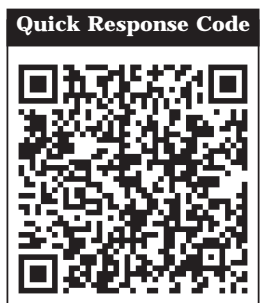

doi: $10.5866 / 2015.7 .10152$

${ }^{1 H}$.O.D

${ }^{2}$ Senior Lecturer

Dept of Pediatric Dentistry,

Faroogia Dental College and Hospital, Faroogia

Educational Complex, Umar khayam Road, Eidgah

Mysore-570021, Karnataka, India

${ }^{3}$ Lecturer

Dept of Pediatric Dentistry

J SS Dental College and Hospital

SS Nagar, Mysore-570015, Karnataka, India

\section{Article Info:}

Received: April 14, 2015

Review Completed: May 12, 2015

Accepted: J une 11, 2015

Available Online: April, 2015 (www.nacd.in)

C NAD, 2015 - All rights reserved

\section{Email for correspondence:}

drsiddu4@gmail.com

\section{INTRODUCTION}

Odontogenic anomalies are the formative defects caused by genetic disturbances or environmental factors during tooth morphogenesis occurrence of multiple anomalies in individuals or families, without evidence of other systemic manifestations or syndromes have rarely been reported. ${ }^{1}$

Hypodontia/tooth agenesis is defined as a common anomaly of human dentition characterized

\begin{abstract}
:
Oligodontia, a form of hypodontia, is commonly seen in permanent than in deciduous dentition. It is defined as the congenital absence of six or more teeth, excluding third molars. It is relatively a rare condition which occurs as an isolated finding or as part of a syndrome. The present paper shows a rare case of oligodontia with ectodermal dysplasia in 2 siblings (boys). Both the cases were associated with dental findings and extra oral findings of Ectodermal Dysplasia (ED). The prevalence, possible etiological factors and treatment options are reviewed.
\end{abstract}

Key words: oligodontia, ectodermal dysplasia type A, selective hypodontia. 
familial triat or as a sporadic finding. ${ }^{5}$ The treatment for this abnormality can be a challenge. ${ }^{6}$ Care often requires multidisciplinary approach. The purpose of this article is to report a rare case of congenitally missing permanent teeth with over retained deciduous dentition in 2 siblings.

\section{CASE REPORT}

A 12 year old boy visited the Department of Pedodontia and Preventive dentistry along with his mother and siblings with a chief complaint of food lodgment and sensitivity in the upper right back region of jaw. On physical evaluation patient didn't reveal any other systemic abnormalities and no skeletal changes but over all dryness of skin, decreased sweat, scaly palm, frontal bossing, and low set ears were present (Figure 1, 2 and 3). Intraoral examination revealed presence of caries lesion with maxillar right first premolar (14). The teeth present were: $55,14,53,52,11,21,63,24,65$, $75,74,73,72,71,81,82,83,84,85$. The missing permanent teeth were: $17,16,15,13,12,22,23,25$, 26, 27, 36, 35, 34, 33, 32, 31,41,42,43,44,45,46. Panoramic radiograph revealed the presence of 47 and 37 tooth buds. There was an evidence of internal root resorption with 72 and external root resorption with 52, 71, 72 and 81 (Figure 4). Other features include conical shaped 11, 21 with diastema (Figure 5).

Since parent was unaware of this condition, same was explained and future consequences were told. Also examination of other two siblings (a boy and a girl) who had accompanied their brother was done. On physical examination same extra-oral features were seen with the boy (F igure 6, 7 and 8). Intraorally bilateral single tooth crossbite with 55, 65 were present. The teeth present include: 55, 54, $53,52,11,21,62,63,64,65,75,74,73,72,71,81$, $82,83,84,85$. The missing teeth include: $17,14,12$, 22, 24, 25, 27, 37, 36, 33, 32, 31, 41, 42, 43, 46. Panoramic radiograph revealed the presence of 13 , $14,16,23,26,34,35,44,45,47$. There is also evidence of external root resorption with $52,62,63$, 53, 81 and meso-taurodontism with 75, 85 (Figure 9). The other features include midline diastema, conical shaped 11, 21 (Figure 10). Based on clinical and radiographic examination, diagnosis of ectodermal dysplasia with oligodontia was made. But the girl being the youngest of the three did not show any findings.

\section{DISCUSSION}

Dental agenesis is the most common devel opmental anomaly in humans, often presenting a significant clinical problem. ${ }^{4}$ Schalk-vander Weide has suggested six and more permanent teeth (excluding third molars) as a criterion for oligodontia which is associated with systemi c manifestations. ${ }^{3,7,8}$ Oligodontia is also known as partial anodontia, severe/advanced hypodontia or selective tooth agenesis. ${ }^{9}$, 10-12

Population studies on the prevalence of hypodontia suggest that majority (>80\%) will present with $1 / 2$ congenitally missing teeth and only $<1 \%$ will present with six or more teeth so, oligodontia is relatively rare condition. ${ }^{7,11}$ The incidence vary from 0.08 to $0.16 \%{ }^{12}$ In a recently published study, a rate of $0.16 \%$ oligodontia was reported. ${ }^{7}$ F requency of congentially missing teeth was higher in girls than in boys. In the present case, occurrence was in boys. The teeth most commonly absent are permanent second premolar and maxillary lateral incisor. ${ }^{12}$ The permanent first molars and maxillary central incisors are the most stable teeth.7, 12, Molar absence, however, is a prominent feature of some forms of isolated oligodontia. ${ }^{12}$

Oligodontia can occur in association with genetic syndromes such as ectodermal dysplasia, incontinentia pigmenti, Down syndrome and Rieger syndrome or as a non syndromic isolated familial triat or as a sporadic finding. 5,12,13, The pattern of tooth absence is influenced by the gene affected, as well as the type of mutation within the specific gene. ${ }^{12}$ It affects permanent rather than deciduous dentition. ${ }^{10}$ When oligodontia is associated with a syndrome there may be abnormalities of the skin, nails, eyes, ears and skeleton. ${ }^{14}$

In severe cases, it is often associated with conical teeth, microdontia and delayed eruption of permanent teeth, an increased freeway space and retention of deciduous teeth and also with taurodontism. ${ }^{14,15}$ Dentoalveolar characteristics include occlusal disturbances like deep-bite, crossbite, attrition, steep inclination of maxillary incisors, ectopic eruption and alteration of tooth morphology. In most cases of non syndromic familial oligodontia it is inherited as an autosomal dominant triat with reduced penetration. ${ }^{5}$ The isolated genes include 


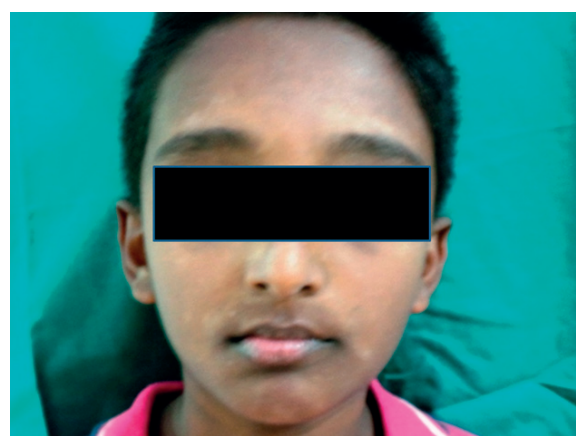

Figurel: Clinical picture showing dryness of face.

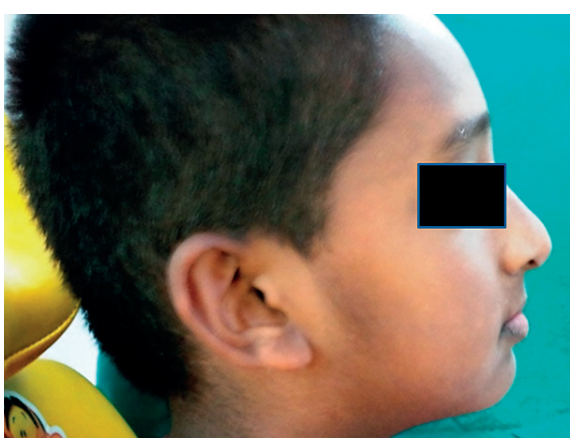

Figure 2: Clinical picture showing frontal bossing and low set ears.

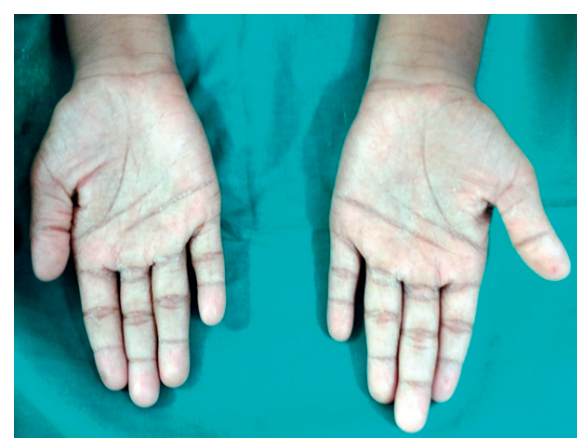

Figure 3: Clinical picture showing scaly palms.

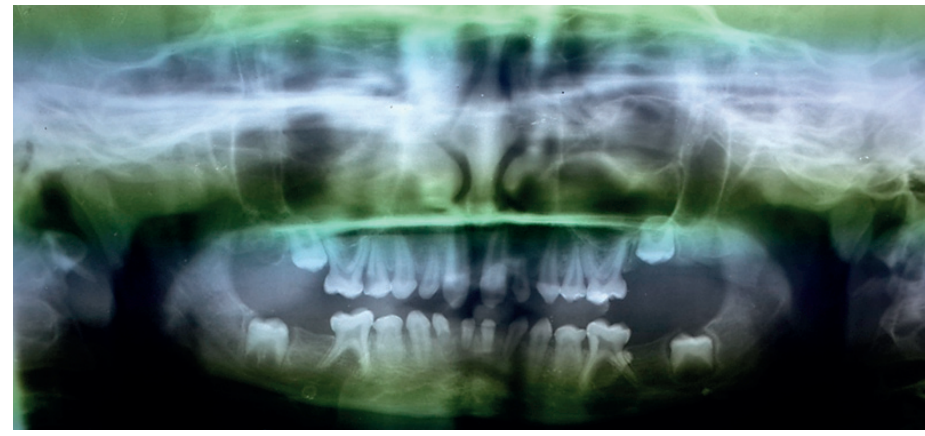

Figure 4: Panoramic radiograph showing presence of 47 and 37 tooth buds. There was an evidence of internal root resorption with 72 and external root resorption with 52, 71, 72 and 81.

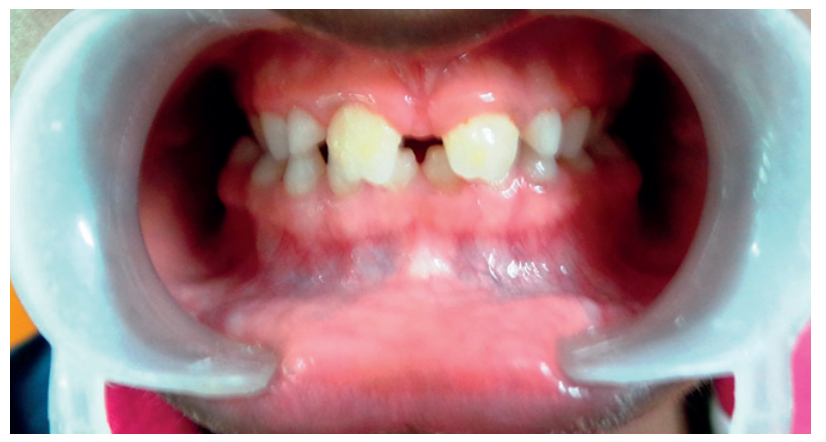

Figure 5: Intra oral picture showing midline diastema with conical centrals.

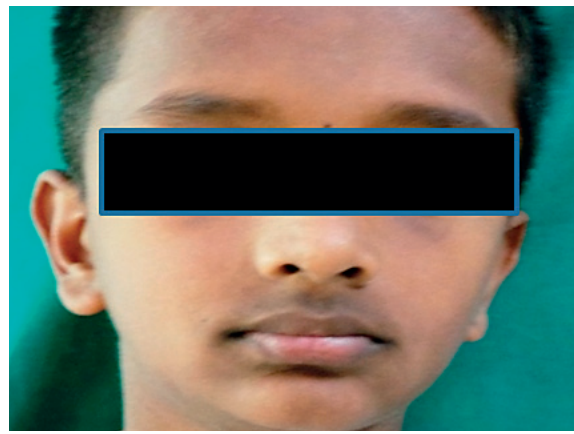

Figure 6: Clinical picture showing dryness of face.

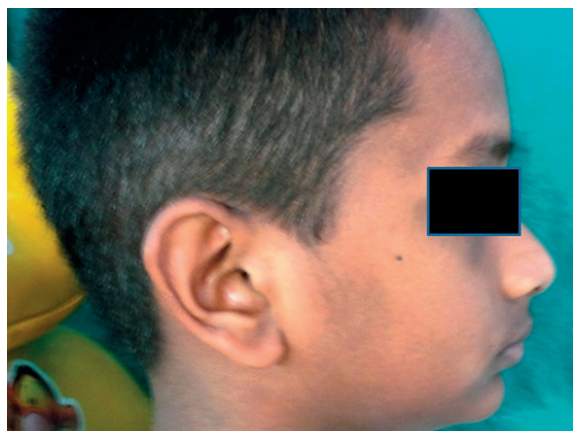

Figure 7: Clinical picture showing frontal bossing and low set ears.

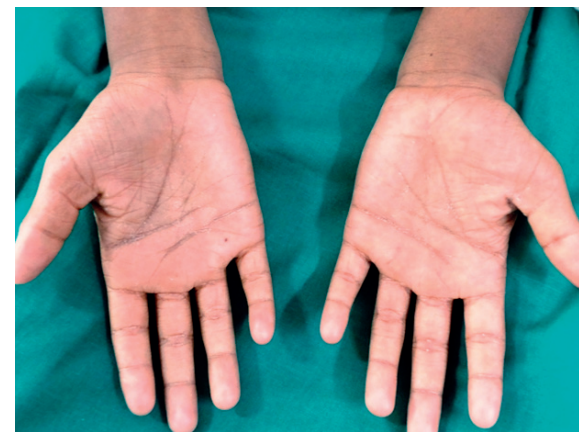

Figure 8: Clinical picture showing scaly palms.

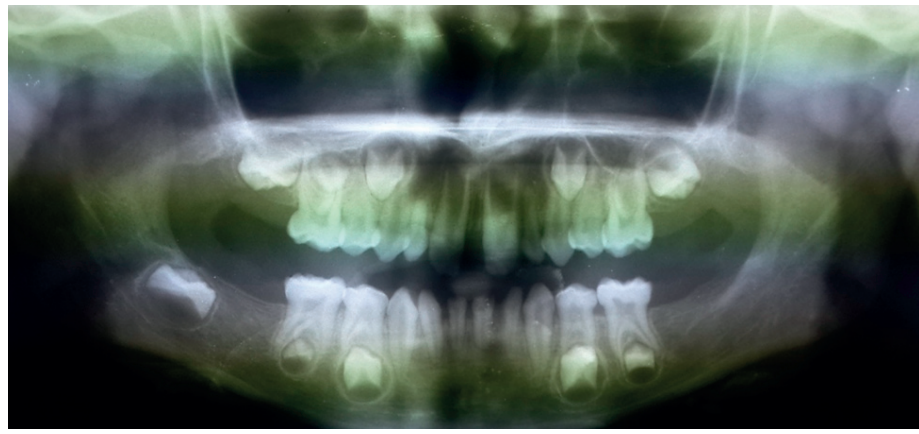

Figure 9: Panoramic radiograph showing mesotaurodontism with 7585

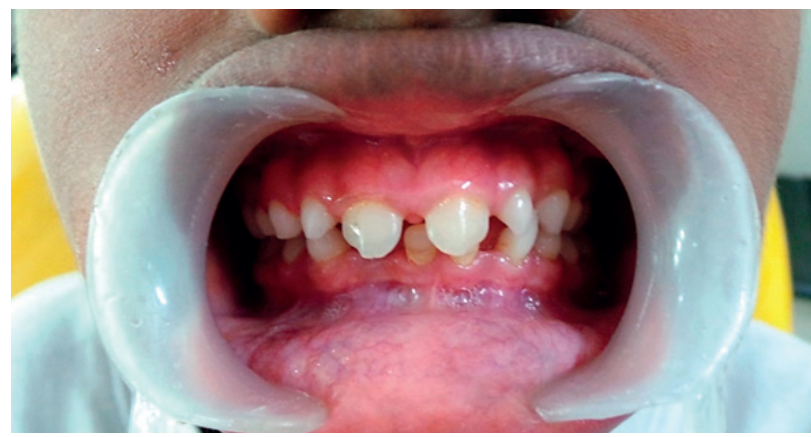

Figure 10: Intra oral picture showing midline diastema with conical centrals. 
MSX1 and PAX9.The third gene involved is LTBP3.The EDA gene encodes a transmembrane protein that is involved in hypodontia/anhydrotic ED which is the most common form of ED which affects men more and features include- heat intolerance, decreased skin colour absence/reduced tears, large forehead.

In pure form of ED (type A) two or more features of ectodermal structures are involved like sweat glands and teeth. In the present case report both the boys had 22 and 16 permanent teeth missing with more than three features of ED. Hence, the present case was diagnosed as ED (type A) with oligodontia. Because of its variable genetic etiology, the presentation and subsequent clinical effect on the dentofacial structures of patients diagnosed with oligodontia may vary greatly. ${ }^{12}$ This leads to social withdrawal, especially in adolescent years. ${ }^{6}$ So, treatment requires a fully integrated interdisciplinary team approach with includes orthodontist, surgeons and prosthodontists. ${ }^{7}$ Also a number of factors to be considered during treatment planning which includes age, number and condition of retained teeth, number of missing teeth, occl usion etc. ${ }^{8}$ Common methods includes pre-restorative orthodontics, restoration with RPD/FPD and implant supported prosthesis. ${ }^{8,16}$ In the first case, 14 was restored with composite. Both the boys were kept under observation, since the parents did not give consent for any treatment.

\section{CONCLUSION}

Understanding such rare conditions like oligodontia with ED and correlating the features present in the case is important, especially when not all features of ED is seen. It's understood only when it's reported $\&$ diagnosed early. I ts evaluation is done to improve the oral health \& psychological distress of the child.

\section{References}

1. Nagaveni NB. An unusual occurrence of multiple dental anomalies in a single non syndromic patient: a case report. Case report in dentistry 2012; 426091.

2. Goldenberg $M$, Das $P$, Messersmith $M$, Stockton D W, Patel $P$ I, D'Souze R N. Clinical, radiographic and genetic evaluation of a novel form of autosomal-dominant oligodontia. J ol dent Res 2000; 79(7):1469-1475.
3. Rolling S, Poulsen S. Oligodontia in Danish school children. Acta odontol scandi 2001; 59:111-112.

4. De Coster $P$ J, Marks L A, Martens L C, Huysseune A. Dental agenesis: Genetic \& clinical perspectives. J ol. Oral pathol med 2009; 38:1-17.

5. Klein M L, Nieminen P, Lammi L, Niebuhr E, Kreiborg S. Novel mutation of the initiation codon of PAX9 causes oligodontia. J Dent Res 2005; 84(1):43-47.

6. Mahadevi B Hosur, R S Puranik, Srinivas S Vanaki . Oligodontia: a case report and review of literature. World jol of dentistry 2011; 2(3):259-262.

7. Worsaae N, J ensen B N, Holm B, Holsko J . Treatment of severe hypodontia- oligodontia:an interdisciplinary concept. Int J Oral Maxillofacial Surg 2007; 36:473-480.

8. Dhanrajani P J . Hypodontia: etiology, clinical features, and management. Quintessence Int.2002; 33:294-302.

9. Avcu N, Buyukkopru D,Kansu O, Dural S. Severe hypodontia and asymptomatic bilaterally ectopic impacted teeth in coronoid processes: a case report. Quintessence int 2004; 35:582-583.

10. Noor A, Wind passenger C, Vitcu I, et al. Oligodontia is caused by mutation in LTBP3, the gene encoding latent TGF-BETA binding protein 3. Am J Human Gen 2009; 84(10):519-523.

11. Larmour C J , Mossey P A, Thind B S, Forgie A H, Stirrups $D$ R. Hypodontia: a retrospective review of prevalence and etiology (part 1). Quintessence int 2005; 36:263-270.

12. Singer $\mathrm{S} L$, Henry $\mathrm{P}$ J, Lander I D. A treatment planning classification for oligodontia. Int. J Prosthodon 2010; 23:99106.

13. Creton M A, Cune M S, Verhoeven W. Patterns of missing teeth in a population of oligodontia pts. Int J Prostho 2007; 20:409-413.

14. Tsai P F, Chiou H R, Tseng C C. Oligodontia: A case report. Quintessence int.1998; 29:191-193.

15. Haselden K, Hobkirk J A, Goodman J R, J ones S P, Hemmings $\mathrm{K} W$. Root resorption in retained deciduous canine and molar teeth without permanent successors in pts with severe hypodontia. Int J of pediatric dentistry 2001; 11:171-178.

16. Finnema K J, Raghoebar G M, Meijer H A, Vissink A. Oral rehabilitation with. Int. J Prosthodont 2005; 18:203-209. 